\title{
Multi-Responsive Behaviors of Copolymers Bearing $N$-Isopropylacrylamide with or without Phenylboronic Acid in Aqueous Solution
}

\author{
Jiaxing Li ${ }^{1}$, Lei Yang ${ }^{1, *(\mathbb{D})}$, Xiaoguang Fan ${ }^{2, *}$, Fei Wang ${ }^{1}$, Jing Zhang ${ }^{1}$ and Zhanyong Wang ${ }^{1}$ (1) \\ 1 School of Environmental and Biological Engineering, Liaoning Shihua University, Fushun 113001, China; \\ babyli824828@yahoo.com (J.L.); feiwang1982@yahoo.com (F.W.); 66zj@163.com (J.Z.); \\ wangzy125@gmail.com (Z.W.) \\ 2 College of Engineering, Shenyang Agricultural University, Shenyang 110866, China \\ * Correspondence: leiyang1982@yahoo.com (L.Y.); xiaoguangfan1982@syau.edu.cn (X.F.); \\ Tel.: +86-024-5686-1705 (L.Y.); +86-024-8848-7119 (X.F.)
}

Received: 30 January 2018; Accepted: 6 March 2018; Published: 9 March 2018

\begin{abstract}
Continuing efforts to develop novel smart materials are anticipated to upgrade the quality of life of humans. Thermo-responsive poly( $N$-isopropylacrylamide) and glucose-responsive phenylboronic acid-typical representatives-are often integrated as multi-stimuli-sensitive materials, but few are available for side-by-side comparisons with their properties. In this study, both copolymers bearing $\mathrm{N}$-isopropylacrylamide (NIPAAm), with or without 3-acrylamidophenylboronic acid (AAPBA), were synthesized by free radical polymerization, and characterized by Fourier transform infrared spectrometry, nuclear magnetic resonance hydrogen spectroscopy and gel permeation chromatography. Dynamic light scattering was used to analyze and compare the responsive behaviors of the copolymers in different aqueous solutions. Atomic force microscopy was also employed to investigate the apparent morphology changes with particle sizes. The results demonstrated that the introduction of NIPAAm endowed the composite materials with thermosensitivity, whereas the addition of AAPBA lowered the molecular weight of the copolymers, intensified the intermolecular aggregation of the nanoparticles, reduced the lower critical solution temperature (LCST) of the composites, and accordingly allowed the copolymers to respond to glucose. It was also concluded that the responding of smart copolymers to operating parameters can be activated only under special conditions, and copolymer dimension and conformation were affected by inter/intramolecular interactions.
\end{abstract}

Keywords: poly( $\mathrm{N}$-isopropylacrylamide); phenylboronic acid; smart responsive behavior; hydrodynamic diameter; dynamic light scattering

\section{Introduction}

Poly( $N$-isopropylacrylamide) (PNIPAAm)-comprising hydrophilic amide bonds and hydrophobic isopropyl groups, empowers hydration-dehydration changes in polymer chains with ambient temperature in aqueous solutions [1]. The products with the PNIPAAm component exhibit lower critical solution temperature (LCST), and often appears as sharp decrease or increase in hydrodynamic diameter $\left(\mathrm{D}_{\mathrm{H}}\right)$ of polymers. Therefore, the changing trend of $\mathrm{D}_{\mathrm{H}}$ along with temperature is usually employed to infer the temperature sensitivity of PNIPAAm-containing materials. Given that the overall structure and surface property of the end products can be changed by temperature control with appropriate design and simplified operation, PNIPAAm and its derivatives are widely used for drug delivery [2], biomacromolecule immobilization [3], intelligent cell culture substrate [4], artificial extracellular matrix [5] and other biomedical fields. Phenylboronic acid (PBA) can ionize in aqueous 
solutions to give uncharged hydrophobic forms and charged hydrophilic forms. The charged forms generate reversible covalent complexes with cis-diol compounds, thus a response to the increasing population of negatively charged PBA will result in the formation of more hydrophilic structure [6]. Glucose addition moderately changes water solubility of PBA-containing materials, which gives them attractive glucose responsiveness. This unique characteristic can be utilized to design a drug-controlled release system [7] and develop a glucose sensor [8]. It is very valuable that the elaborate combination of stimuli-responsive polymers with such advanced structure can produce novel materials with virtues from both moieties [9]. More attempts have been made to create multiresponsive materials, especially for dual responses to temperature and glucose.

Dynamic light scattering (DLS) is a technique in physics that can be applied to determine the size distribution profile of small particles in suspension or polymers in solution [10]. Because it is easy to change physical conditions of working solutions, DLS technique is often used to examine $\mathrm{D}_{\mathrm{H}}$ of PNIPAAm-mediated materials changed in response to the changes of environmental parameters, in order to illustrate the stimulus responses of intelligent composites [11-13]. Recently, scholars had also conducted prominent works in the synthesis of smart materials carrying NIPAAm and PBA, and further investigated their dual responses to temperature and glucose by means of the DLS technique [14-18]. It can be seen that PBA moieties are supposed to be modified on PNIPAAm backbone, making it easier to upgrade the thermosensitivity of PNIPAAm to multiple responses to temperature, $\mathrm{pH}$ and glucose, so their effective applications can be further expanded.

In our previous study, we had prepared PNIPAAm-containing copolymers and determined their temperature responses in various aqueous solutions with different temperature, $\mathrm{pH}$ value, species and concentrations of salts by DLS [19]. Our results demonstrated that the intervention of hydrophilic/hydrophobic reactants, salt substances and $\mathrm{pH}$ reagents could change the type or strength of inter/intramolecular acting forces between polymers, so the conformation changes of polymer molecules were different from what occurred in ultrapure water. If PBA is designedly introduced into the molecular segments of PNIPAAm-based copolymers, it is bound to bring inestimable impacts on the physical properties of temperature-responsive polymers, particularly for intelligent responses. The research on performance comparison between the copolymers bearing NIPAAm with or without PBA is limited, but it is the point of this study with particular emphasis on the influence of measurement temperature, $\mathrm{pH}$ and carbohydrate on the stimulus responses of both copolymers. Simultaneously, particle size, morphology as well as LCST are also essential to understand the interplay between smart behavior, polymer structure and driving force [20]. This is also the focus of our study.

In this study, the novel P(NIPAAm-co-AAPBA-co-HPM-co-TMSPM) copolymers were synthesized by free radical polymerization of $N$-isopropylacrylamide (NIPAAm), 3-acrylamidophenylboronic acid (AAPBA), hydroxypropyl methacrylate (HPM) and 3-trimethoxysilylpropyl methacrylate (TMSPM), while P(NIPAAm-co-HPM-co-TMSPM) copolymers prepared from the same synthesis conditions were used as opponents. The following measurements were performed in succession to analyze and compare the copolymers bearing NIPAAm with or without AAPBA. Fourier transform infrared (FT-IR) spectrometry, nuclear magnetic resonance hydrogen $\left({ }^{1} \mathrm{H}-\mathrm{NMR}\right)$ spectroscopy and gel permeation chromatography (GPC) were employed to identify the chemical structure, molecular composition and molecular weight of the end products. Importantly, DLS technique was applied to determine the $\mathrm{D}_{\mathrm{H}}$ of both copolymers in ultrapure water and aqueous solutions with different temperature, $\mathrm{pH}$ value and glucose concentration, so as to analyze the influences of inter/intramolecular interactions on copolymer size and conformation. Atomic force microscopy (AFM) were used to display visually the particle sizes of the copolymers deposited on glass surfaces, which can offer more auxiliary information for smart responsive behaviors of the copolymers. 


\section{Materials and Methods}

\subsection{Materials}

NIPAAm, HPM, TMSPM and 2,2-azobisisobutyronitrile (AIBN) were purchased from Aladdin (Shanghai, China). AAPBA was supplied by J\&K Scientific (Beijing, China). NIPAAm, AAPBA and AIBN were fully recrystallized respectively followed by freeze-drying. The others including hydrochloric acid $(\mathrm{HCl})$, sodium hydroxide $(\mathrm{NaOH})$, absolute ethanol and glucose were provided by Aldrich. UHQ water was derived from Millipore-Q ultrapure water purification system (Millipore Corporation, Molsheim, France).

\subsection{Copolymer Synthesis and Identification}

The synthesis and identification of the copolymers bearing NIPAAm with or without AAPBA were conducted according to the reported protocols with some modifications $[19,21,22]$. Briefly, P(NIPAAm-co-AAPBA-co- HPM-co-TMSPM) (PNAHT for short) copolymers and P(NIPAAm-co-HPM-co-TMSPM) (PNHT for short) copolymers were synthesized by free radical polymerization of NIPAAm, AAPBA, HPM and TMSPM with the initial molar ratios of 20:1:1:1 and 20:0:1:1 respectively, initiated by AIBN (1\% of total molar quantities for all reactants) at $60{ }^{\circ} \mathrm{C}$ for $12 \mathrm{~h}$ under nitrogen, then precipitated and freeze-dried under vacuum for $24 \mathrm{~h}$, and finally stored in a refrigerator for further use.

The FT-IR spectra were used to analyze the functional groups of the copolymers via Nicolet Magna 750 FT-IR spectrometer (Nicolet Instrument Corporation, Madison, WI, USA) in the wavenumber range of 4000 500 $\mathrm{cm}^{-1}$. The ${ }^{1} \mathrm{H}-\mathrm{NMR}$ spectra were applied to identify the molecular compositions of the compounds through Bruker Avance $400 \mathrm{MHz}$ NMR spectrometer (Bruker Corporation, Fallanden, Switzerland). The GPC (PL-GPC-50, Varian Inc., Palo Alto, CA, USA) was employed to determine the molecular weight distribution and polymerization degree of the composites.

\subsection{Smart Responsive Behaviors of Copolymers}

PNAHT and PNHT copolymers were respectively dissolved at the final concentration of $1.0 \mathrm{mg} \cdot \mathrm{mL}^{-1}$ in absolute ethanol, UHQ water and aqueous solutions with different $\mathrm{pH}$ values (1.0 12.0) and glucose concentrations $\left(0 \sim 6.0 \mathrm{mg} \cdot \mathrm{mL}^{-1}\right)$, and then stirred at room temperature for $12 \mathrm{~h}$. Prior to adding $1.0 \mathrm{~mL}$ sample into a cuvette, the copolymer solutions were filtrated and purified with Millipore filter $(0.2 \mu \mathrm{m})$ to remove any impurities. The cuvette was then placed in the bath of Malvern DLS Nanosizer (NanoZS90, Malvern Instruments Ltd., Malvern, UK) with scattering angle fixed at $90^{\circ}$. The measurements were performed from $15^{\circ} \mathrm{C}$ to $40^{\circ} \mathrm{C}$ with lower temperature fluctuation $\left( \pm 0.1^{\circ} \mathrm{C}\right)$. The $\mathrm{pH}$ values or glucose concentrations of the solutions to be tested were modulated by changing the content of $\mathrm{HCl}$ or $\mathrm{NaOH}$ or glucose. To improve accuracy and comparability of experimental results, the data was collected after $10 \mathrm{~min}$ when the solutions had reached the setting parameters. Each correlation curve was accumulated 30 50 times to eliminate noise, and at least three replicates were carried out under the same conditions. The average value \pm standard deviation was applied to present the $\mathrm{D}_{\mathrm{H}}$ of copolymers obtained by volume distribution under different conditions. DLS data were analyzed using Malvern Zetasizer Software v7.11.

\subsection{Morphology Analysis of Glass Surfaces with Copolymer Deposition}

The glass coverslips were treated by constant velocity-dip coating of different aqueous solutions with the same copolymer concentration of $1.0 \mathrm{mg} \cdot \mathrm{mL}^{-1}$, which allowed for observing the particle sizes of PNAHT and PNHT copolymers under various working conditions. The fast-drying technique was also introduced to keep the copolymer particles deposited on glass surfaces with original states as much as possible in respective solutions in spite of some conformation changes caused by dehydration. The outlet air temperatures of dryer were in accordance with the temperature of working solutions as closely as possible. Then the morphology of coated coverslips were scanned by AFM (solve P47, 
NT-MDT Spectrum Instruments, Moscow, Russia). Three trials were randomly selected in each sample with different scanning sizes. The surface characteristic parameters of samples were obtained from Nova 1.1.0.1918 Software.

\section{Results and Discussion}

\subsection{Copolymer Synthesis and Identification}

\subsubsection{Synthesis of PNAHT and PNHT Copolymers}

PNAHT and PNHT copolymers have been shown to have good responses to temperature or glucose in aqueous solutions on the evidences of the follow-up measurements, but the intelligent copolymers in their current forms of molecular chains will not be used for practical applications. However, both copolymers bearing siloxane bonds can couple with hydroxyl-contained substrates with any shape and dimension by heating or radiation [23]. Meanwhile, HPM can provide effective hydroxyl groups for intermolecular bonding of copolymers, so there are nanoparticles depositing on two- or three-dimensional surfaces to form films with certain thickness. It can be concluded that synthesis of copolymers with smart responses is the premise and foundation for subsequent preparation of functional films. Furthermore, copolymer performance in response to environmental factors directly decides further applications of copolymer films. Therefore, component kinds and compounding ratios of resultant composites are key elements for film preparation, performance tuning and scheduling optimization. NIPAAm, AAPBA, HPM and TMSPM selected in this study are all unsaturated monomers with double bonds. The copolymers can be synthesized from three or four monomers by free radical polymerization, where NIPAAm and AAPBA used as primary reactants will provide their functional groups which enable them to have temperature and glucose responses. The recent studies suggested that larger PBA content gave rise to stronger glucose responsiveness for the end products $[6,17,24]$, but excessive dosage could restrict the thermo-sensitivity of copolymers. Actually, we attempted various mole ratios of NIPAAm to AAPBA (such as 20:1, 10:1, 5:1 and so on), but it was found that adding overmuch AAPBA to the composites would result in interchain aggregation even at room temperature, and the formed clusters were difficult to pass through Millipore filters. Thus, the mole ratio between NIPAAm and AAPBA was designed to 20:1 for PNAHT copolymers. HPM and TMSPM can provide sufficient hydroxyl groups and siloxane bonds for the formation of intelligent copolymer films. It is recommended to use 5\% addition of NIPAAm for both HPM and TMSPM [25]. So the initial molar ratios of NIPAAm, AAPBA, HPM and TMSPM were determined to be 20:1:1:1 and 20:0:1:1 respectively for PNAHT and PNHT copolymers in this study. The diagrams for molecular structure of both copolymers were shown in Figure 1.

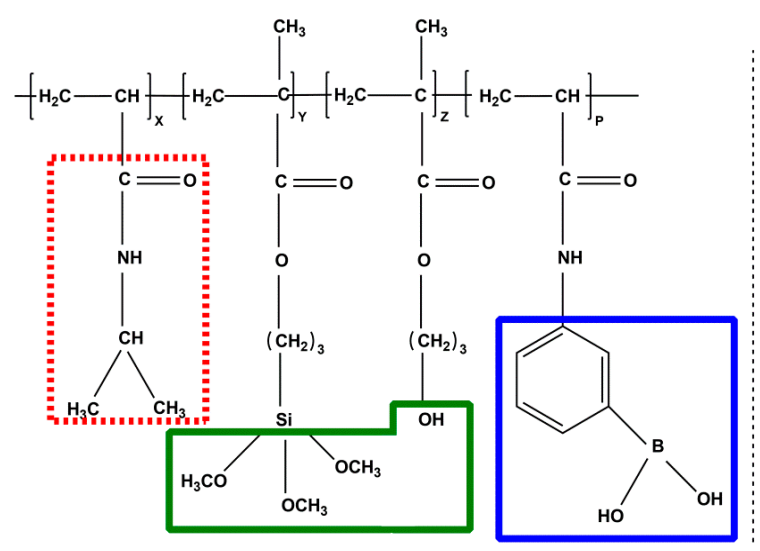

(A)

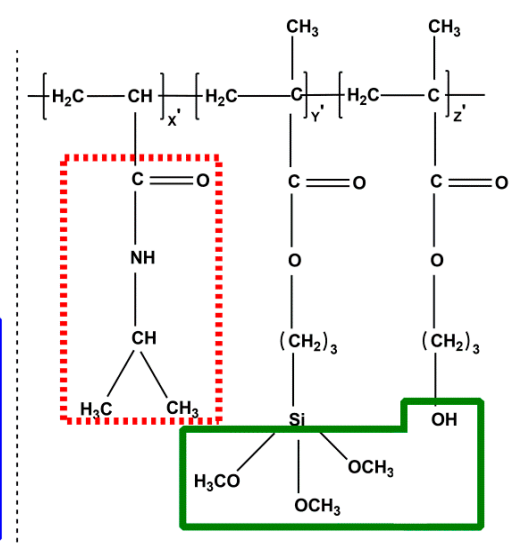

(B)

Figure 1. Molecular structure of PNAHT (A) and PNHT (B) copolymers. 


\subsubsection{Identification of PNAHT and PNHT Copolymers}

Figure 2 displayed FT-IR spectra for PNAHT and PNHT copolymers. As shown in Figure 2A, the stretching vibration absorption peak of amide bond I and the bending vibration absorption peak of amide bond II were detected at $1652 \mathrm{~cm}^{-1}$ and $1550 \mathrm{~cm}^{-1}$, belonging to NIPAAm and AAPBA. The symmetrical deformation vibration absorption peaks of isopropyl bond discovered at $1389 \mathrm{~cm}^{-1}$ and $1369 \mathrm{~cm}^{-1}$, were typical absorption peaks of NIPAAm [26]. The peak at $1340 \mathrm{~cm}^{-1}$ was characteristic absorption peak of boric acid groups [27], and the peak at $709 \mathrm{~cm}^{-1}$ was the out-of-plane bending vibration absorption peak of benzene ring, which were assigned to AAPBA. The wider absorption peak appearing within $3100 \sim 3700 \mathrm{~cm}^{-1}$ could be due to the superposition of the stretching vibration absorption peaks of hydroxyl group and amide bond II, indirectly proving the presence of HPM, NIPAAm and AAPBA. The stretching vibration absorption peaks at $1270 \mathrm{~cm}^{-1}, 1079 \mathrm{~cm}^{-1}$ and $799 \mathrm{~cm}^{-1}$ indicated that siloxane bonds were integrated into the copolymers. Absorption peaks at $1722 \mathrm{~cm}^{-1}$ and $1173 \mathrm{~cm}^{-1}$ were attributed to the stretching vibration absorption peaks of ester groups derived from HPM and TMSPM. The results confirmed that the functional groups of four reactants existed in PNAHT copolymers. The characteristic absorption peaks in Figure 2B showing a similar correlation to the results of Figure 2A except the absence of functional groups related to PBA, revealed that PNHT copolymers were synthesized from NIPAAm, HPM and TMSPM.

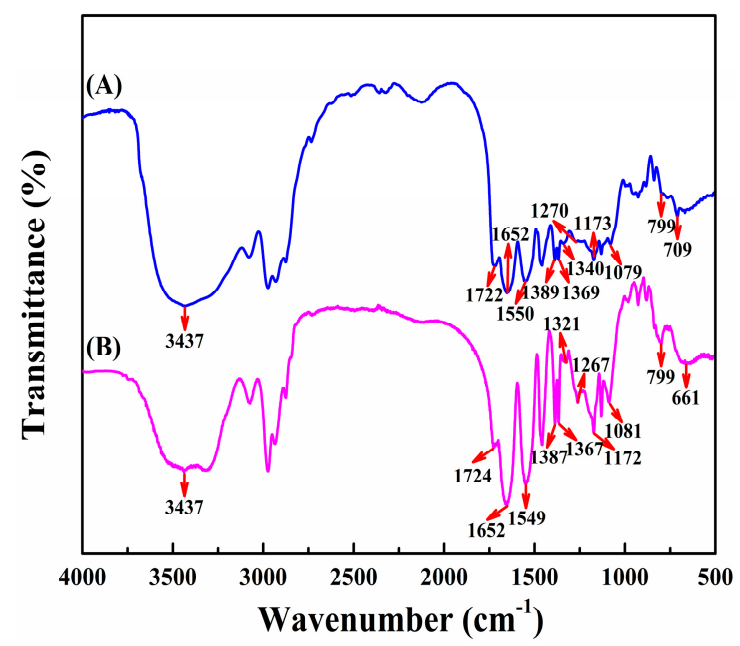

Figure 2. FT-IR spectra of PNAHT (A) and PNHT (B) copolymers.

Figure 3 illustrated ${ }^{1} \mathrm{H}-\mathrm{NMR}$ spectra $\left(500 \mathrm{MHz}, \mathrm{CDCl}_{3}\right)$ of PNAHT and PNHT copolymers respectively. It was well-known that PNHT copolymers were not involved AAPBA during synthetic process. There was a peak appearing at $7.26 \mathrm{ppm}$ in Figure 3B, but the peak intensity was obviously weaker than that of PNAHT group at the same chemical shift, so it was most likely a solvent peak. The integral area of solvent peak must be excluded when analyzing PNAHT group. ${ }^{1} \mathrm{H}-\mathrm{NMR}$ spectra of PNAHT copolymers was shown in Figure 3A, as described below. $\delta(0.75 \sim 1.50 \mathrm{ppm})$, a $\left(\mathrm{Si}-\mathrm{CH}_{2}-\right)$ and $\mathrm{b}\left(-\mathrm{CH}_{3}\right) ; \delta(1.50 \sim 2.33 \mathrm{ppm}), \mathrm{c}\left(-\mathrm{CH}_{2}-\right)$ and $\mathrm{d}(-\mathrm{CH}-) ; \delta(3.49 \mathrm{ppm}), \mathrm{e}\left(-\mathrm{OCH}_{3}\right) ; \delta(3.71 \mathrm{ppm})$, $\mathrm{f}\left(-\mathrm{OCH}_{2}-\right) ; \delta(3.78 \sim 4.22 \mathrm{ppm}), \mathrm{g}(\mathrm{N}-\mathrm{CH}-) ; \delta(7.26 \mathrm{ppm}), \mathrm{h}\left(-\mathrm{C}_{6} \mathrm{H}_{4}-\right)$. The ratio of integral area of characteristic peaks was approximate to 128:71:9:6:20:4, therefore the molar ratio of NIPAAm, AAPBA, HPM and TMSPM in the end product was 20:1:1:1. For PNHT copolymers, peak distributions were as followed. $\delta(0.74 \sim 1.47 \mathrm{ppm})$, a ( $\left.\mathrm{Si}-\mathrm{CH}_{2}-\right)$ and b $\left(-\mathrm{CH}_{3}\right) ; \delta(1.47 \sim 2.49 \mathrm{ppm}), \mathrm{c}\left(-\mathrm{CH}_{2}-\right)$ and d $(-\mathrm{CH}-)$; $\delta(2.49 \sim 3.31 \mathrm{ppm}), \mathrm{e}\left(-\mathrm{OCH}_{3}\right) ; \delta(3.46 \mathrm{ppm}), \mathrm{f}\left(-\mathrm{OCH}_{2}-\right) ; \delta(3.59 \sim 4.34 \mathrm{ppm}), \mathrm{g}(\mathrm{N}-\mathrm{CH}-)$. The ratio of integral area of characteristic peaks was approximately equal to 128:68:9:6:20, and thus the molar ratio of NIPAAm, HPM and TMSPM in PNHT copolymers was deduced as 20:1:1. Figure 3 indicated common traits as well as differences between the two spectra. Both displayed the characteristic peaks of hydrogen derived from NIPAAm, HPM and TMSPM, however, increased chemical shift of characteristic 
peaks and enhanced peak intensity at $7.26 \mathrm{ppm}$ proved the existence of AAPBA in PNAHT copolymers. The analysis results were consistent with the principal objective of copolymer designs.

The molecular weights of PNAHT and PNHT copolymers were determined by GPC, and polymer unit of both copolymers were deduced by ${ }^{1} \mathrm{H}-\mathrm{NMR}$ spectra, and accordingly the degree of polymerization was calculated. The data were summarized in Table 1 . The results indicated that the molecular weight distributions of both copolymers were relatively narrow and the molecular weights of the end products were relatively small. It was concluded that PNHT copolymers exceeded the opponents when comparing their molecular weights and polymerization degree. This was possibly because the stereo-hindrance effect of AAPBA inhibited the polymerization of unsaturated monomers to some extent. Furthermore, we also found that the molecular weights of PNAHT copolymers got smaller with the increase of AAPBA content. The observation was also a positive evidence for the above assumption.

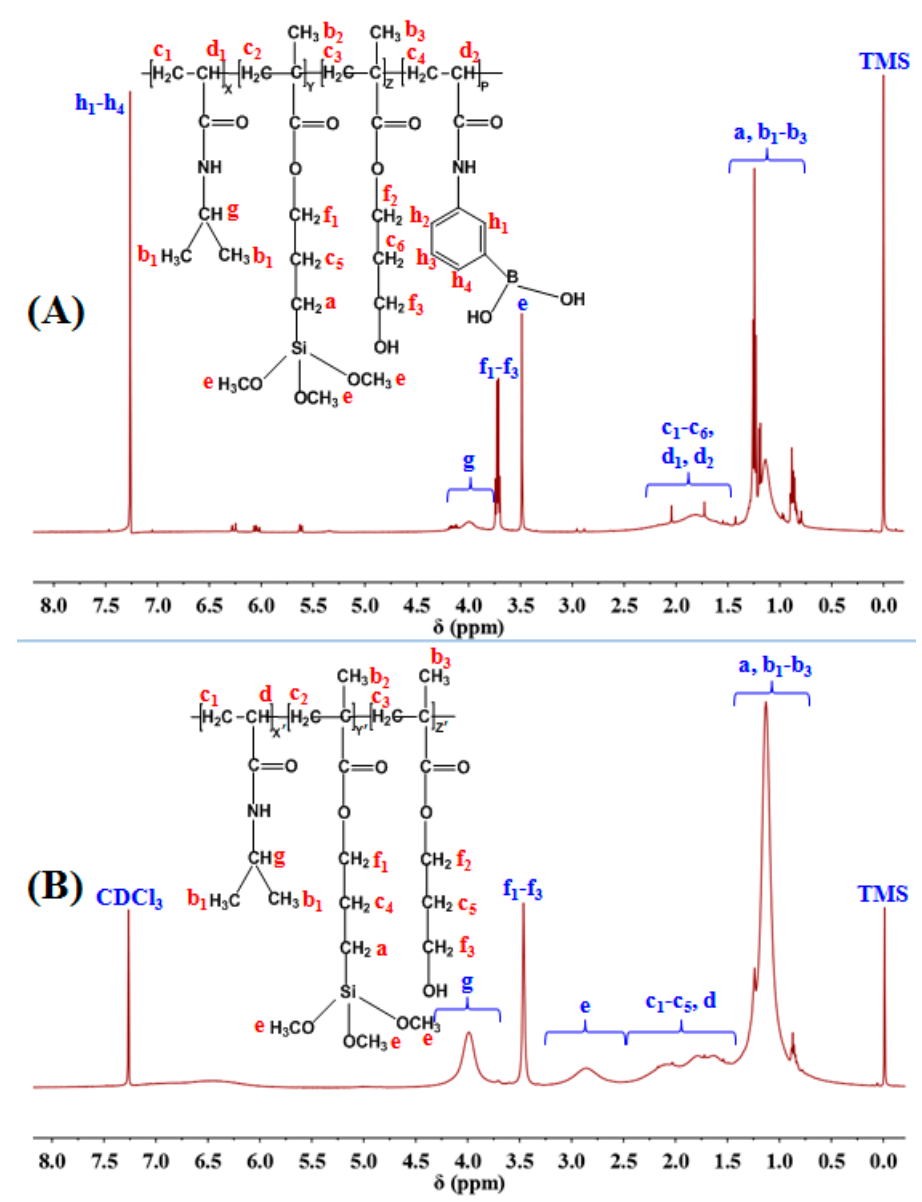

Figure 3. ${ }^{1} \mathrm{H}-\mathrm{NMR}$ spectra of PNAHT (A) and PNHT (B) copolymers.

Table 1. Molecular composition of PNAHT and PNHT copolymers.

\begin{tabular}{|c|c|c|c|c|c|c|c|c|c|}
\hline \multirow{2}{*}{ Group } & \multicolumn{4}{|c|}{ Molar Ratio } & \multirow{2}{*}{$\begin{array}{c}M_{u} \\
\left(\mathrm{~g} \cdot \mathrm{mol}^{-1}\right)\end{array}$} & \multirow{2}{*}{$\begin{array}{c}M_{n} \\
\left(\mathrm{~g} \cdot \mathrm{mol}^{-1}\right)\end{array}$} & \multirow{2}{*}{$\begin{array}{c}M_{w} \\
\left(\mathrm{~g} \cdot \mathrm{mol}^{-1}\right)\end{array}$} & \multirow{2}{*}{$M_{w} / M_{n}$} & \multirow{2}{*}{$D_{P}$} \\
\hline & NIPAAm & TMSPM & HPM & AAPBA & & & & & \\
\hline PNAHT & $\begin{array}{c}X \\
20\end{array}$ & $\begin{array}{l}\mathrm{Y} \\
1\end{array}$ & $\begin{array}{l}Z \\
1\end{array}$ & $\begin{array}{l}\mathrm{P} \\
1\end{array}$ & 2846.76 & 15182 & 24061 & 1.584 & 6 \\
\hline PNHT & $\begin{array}{l}X^{\prime} \\
20\end{array}$ & $\begin{array}{l}Y^{\prime} \\
1\end{array}$ & $\begin{array}{c}Z^{\prime} \\
1\end{array}$ & $\begin{array}{c}\mathrm{P}^{\prime} \\
0\end{array}$ & 2655.77 & 19475 & 29115 & 1.495 & 8 \\
\hline
\end{tabular}

Note: $M_{u}$ represents molecular weight of polymer unit; $M_{n}$ represents number average molecular weight; $M_{w}$ represents weight average molecular weight; $M_{w} / M_{n}$ represents polydispersity index; $D_{P}$ represents degree of polymerization, $D_{P}=M_{n} / M_{u}$. 


\subsection{Smart Responsive Behaviors of Copolymers}

\subsubsection{Copolymers in Absolute Ethanol}

Absolute ethanol was good solvent for PNAHT and PNHT copolymers, so the trend of average hydrodynamic diameter $\left(\mathrm{D}_{\mathrm{AH}}\right)$ of both copolymers changing with temperature in absolute ethanol was first determined. Throughout the temperature ranging from 15 to $40^{\circ} \mathrm{C}, \mathrm{D}_{\mathrm{AH}}$ of PNAHT and PNHT copolymers showing little changes, were $36.95 \pm 2.13 \mathrm{~nm}$ and $43.13 \pm 1.54 \mathrm{~nm}$ respectively, indicating that the copolymers synthesized in this study were short-chain polymers. In absolute ethanol, both copolymers had unfolded conformation without detectable nanoparticle aggregation, therefore DLS data could relatively truly represent the sizes of single chains of the copolymers. Once added AAPBA, $\mathrm{D}_{\mathrm{AH}}$ of PNAHT copolymers decreased, owing to the case that the stereo-hindrance effect of PBA groups terminated the synthetic process of the copolymers in advance.

\subsubsection{Copolymers in UHQ Water}

Figure 4 illustrated the representative DLS profiles plotted in volume distribution versus copolymer $\mathrm{D}_{\mathrm{H}}$ in UHQ water. At $15{ }^{\circ} \mathrm{C}, \mathrm{D}_{\mathrm{H}}$ of PNAHT copolymers distributed from 15.69 to $58.77 \mathrm{~nm}$ with the peak appearing at $28.21 \mathrm{~nm}$ and PDI of 0.189 , while $\mathrm{D}_{\mathrm{H}}$ of PNHT copolymers distributed within 10.1 43.82 nm with the peak centered at $15.69 \mathrm{~nm}$ and PDI of 0.148 . The results revealed that both copolymers were soluble in water without any obvious aggregation at lower temperature. But it was amazing that $\mathrm{D}_{\mathrm{H}}$ of PNAHT and PNHT copolymers in UHQ water were significantly smaller than those in absolute ethanol under the same environment, indicating that the copolymers had properly adjusted their configurations of molecular chains in UHQ water. The hydrogen bonds and hydrophobic interactions produced by hydrophilic and hydrophobic groups of the copolymers in water came to a dynamic balance, so the copolymer chains actually could not extend as they did in absolute ethanol. In addition, $\mathrm{D}_{\mathrm{H}}$ of PNHT copolymers were obviously lower than that of PNAHT copolymers, which would probably be the comparison between single molecular chains of PNHT copolymers and oligomers (aggregated from several molecular chains) of PNAHT copolymers. The $\mathrm{pH}$ of UHQ water was less than $\mathrm{p} K_{\mathrm{a}}$ of AAPBA, therefore PNAHT copolymers were mainly uncharged and hydrophobic in UHQ water, undoubtedly increasing the hydrophobic interactions between the copolymers. However, AAPBA content accounted for only $5 \%$ of molar quantity of NIPAAm, so the hydrophilic shells were also formed by hydrogen bonds between water molecules and hydrophilic groups of the copolymers, accordingly PNAHT copolymers could only aggregate to small clusters. As a result, $\mathrm{D}_{\mathrm{H}}$ of PNAHT copolymers were larger than that of control group in macroscopic manner. Obvious changes of $\mathrm{D}_{\mathrm{H}}$ for PNAHT and PNHT copolymers started at 23 and $27^{\circ} \mathrm{C}$ respectively, demonstrating that addition of hydrophobic AAPBA would significantly reduce LSCT of the resultant copolymers. At $30^{\circ} \mathrm{C}, \mathrm{D}_{\mathrm{H}}$ peaks of PNAHT and PNHT copolymers shifted to $164.2 \mathrm{~nm}$ with distribution between 78.82 and $458.7 \mathrm{~nm}$ with PDI of 0.060 and 0.039 respectively, illustrating that water molecules bound with copolymers were gradually released. The continuously increased hydrophobic interactions and hydrogen bonds between the copolymers could enhance interchain aggregation, thus increasing the overall sizes of the agglomerates. As the temperature rose to $35^{\circ} \mathrm{C}, \mathrm{D}_{\mathrm{H}}$ of PNHT copolymers continued to be expanding, with the peak at $255 \mathrm{~nm}$ and a wider distribution (105.7 531.2 nm) with PDI of 0.048. The volume distribution of PNHT copolymers at $40{ }^{\circ} \mathrm{C}$ was nearly the same with that at $35^{\circ} \mathrm{C}$. The results demonstrated that copolymer aggregation was constantly growing but did not unlimited, and it would be stopped once various kinds of inter/intramolecular forces kept a dynamic balance. Nevertheless, $\mathrm{D}_{\mathrm{H}}$ of PNAHT copolymers had no significant changes within the temperature between 27 and $40{ }^{\circ} \mathrm{C}$, indicating that there were only slight regulations with respect to the structure of molecular chains of PNAHT copolymers. In conclusion, when the temperature was lower than their LCST, both PNAHT and PNHT copolymers remained in hydrated state. Introduction of AAPBA obviously decreased the initial temperature for intermolecular aggregation of the constructed nanoparticles. When the temperature had risen to above LCST, the 
unfolded molecular chains of the copolymers began to aggregate from various directions and stopped at force balance, where large-size and widely-distributed nanometer agglomerations would be formed, showing an increase in $\mathrm{D}_{\mathrm{H}}$ of copolymers.

The thermosensitive characters of the copolymers were characterized by variation tendency of $\mathrm{D}_{\mathrm{AH}}$ with temperature, as displayed in Figure 5. When the temperature was lower than $23^{\circ} \mathrm{C}, \mathrm{D}_{\mathrm{AH}}$ of PNAHT copolymers was around $30 \mathrm{~nm}$, indicating that the nanoparticles were hydratable. The copolymer solution looked clear and transparent. At this point, three kinds of hydrated hydrogen bonds between water molecules and hydrophilic groups including amide bonds, hydroxyl groups and siloxane bonds, were considered as major forces to prevent intermolecular aggregation and intramolecular collapse of the copolymers. However, introduction of AAPBA would undoubtedly enhance hydrophobic interactions, leading to copolymer aggregation and LCST reduction. Across $23{ }^{\circ} \mathrm{C}$, the scattered nanoparticles gathered obviously and become dehydrated. The transparent aqueous solution began to turn opaque. It can be deduced that the LCST of PNAHT copolymers was close to $23^{\circ} \mathrm{C}$. As the temperature continued to rise, six-fold $\mathrm{D}_{\mathrm{AH}}$ could be observed, demonstrating that the molecular chains of PNAHT copolymers aggregated dramatically due to the formation of hydrophobic interactions caused by isopropyl groups and PBA groups as well as hydrogen bonds between amide bonds, but there were still three kinds of hydrated hydrogen bonds. That was to say, the maximum $\mathrm{D}_{\mathrm{AH}}$ of the resultant copolymers were obtained under the actions of two kinds of hydrophobic interactions and four kinds of hydrogen bonds. Figure 5 also revealed when the temperature dropped below $27^{\circ} \mathrm{C}$, PNHT copolymers had $\mathrm{D}_{\mathrm{AH}}$ of around $16 \mathrm{~nm}$. The molecular chains of the copolymers started to aggregate at $27^{\circ} \mathrm{C}$, therefore the LCST of PNHT copolymers in UHQ water could be recognized as $27^{\circ} \mathrm{C}$. When the temperature was higher than LCST, $\mathrm{D}_{\mathrm{AH}}$ of PNHT copolymers were elevated to $270 \mathrm{~nm}$ with PDI of $0.050\left(40^{\circ} \mathrm{C}\right)$, which were apparently larger than the results of PNAHT copolymers $(183 \mathrm{~nm}, 0.053)$. This could be due to the fact that additional hydrophobic interactions derived from PBA groups led to the formation of more compact nanoaggregates.
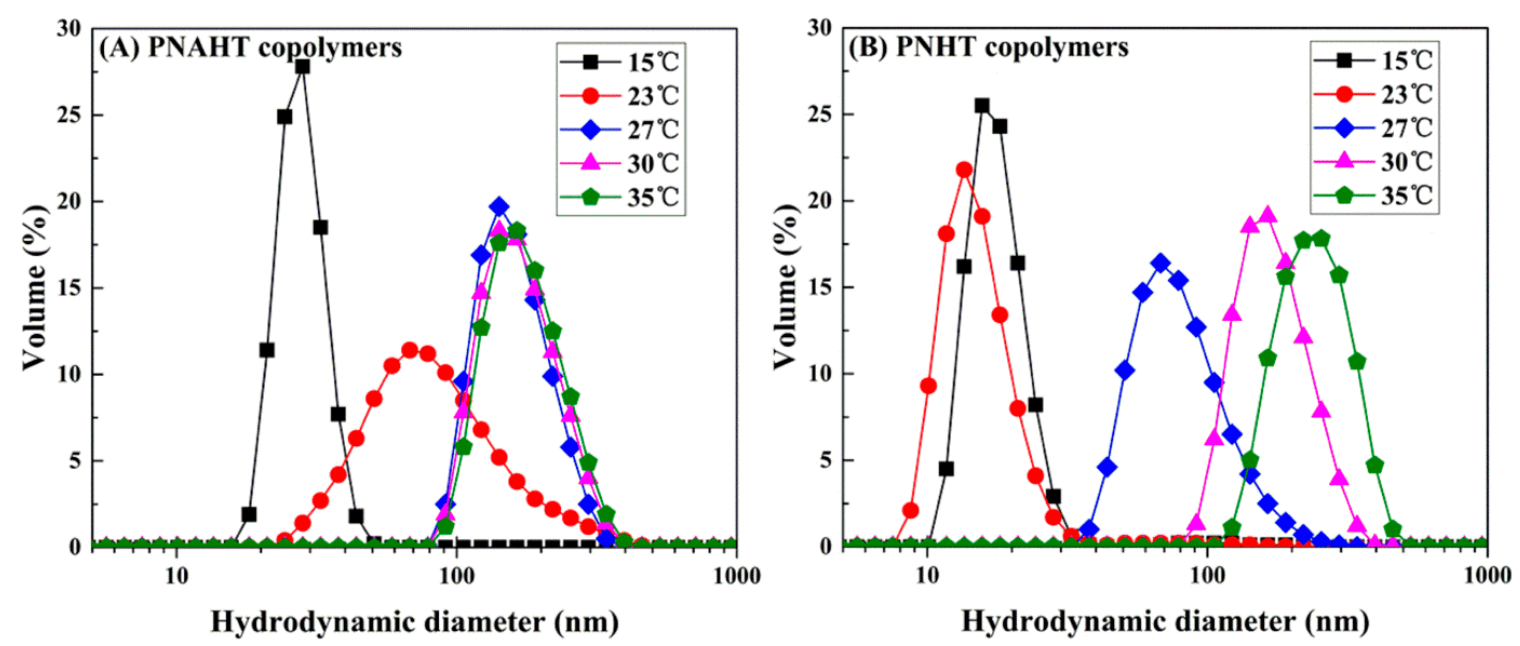

Figure 4. Typical $\mathrm{D}_{\mathrm{H}}$ distributions of PNAHT (A) and PNHT (B) copolymers in UHQ water at different temperatures.

\subsubsection{Copolymers in Acidic or Alkaline Solution}

Pure PNIPAAm homopolymers have actually no response to $\mathrm{pH}$, but the $\mathrm{pH}$ and temperature dual stimuli-responsive behaviors of PNIPAAm-based materials can be obtained via copolymerization with hydrophilic or hydrophobic monomers [28]. At room temperature, the solution $\mathrm{pH}$ of PNAHT and PNHT copolymers with final concentration of $1.0 \mathrm{mg} \cdot \mathrm{mL}^{-1}$ were 6.2 and 6.6 respectively, showing weak acidity. Therefore, both copolymers were not easily ionized and remained uncharged forms in acidic solution, whereas they could be ionized to produce charged nanoparticles in neutral and 
alkaline media. Since apparent $\mathrm{p} K_{\mathrm{a}}$ of PBA and derivatives were approximate to 8.6 [18], AAPBA addition had largely potential to delay the ionization of PNAHT copolymers.

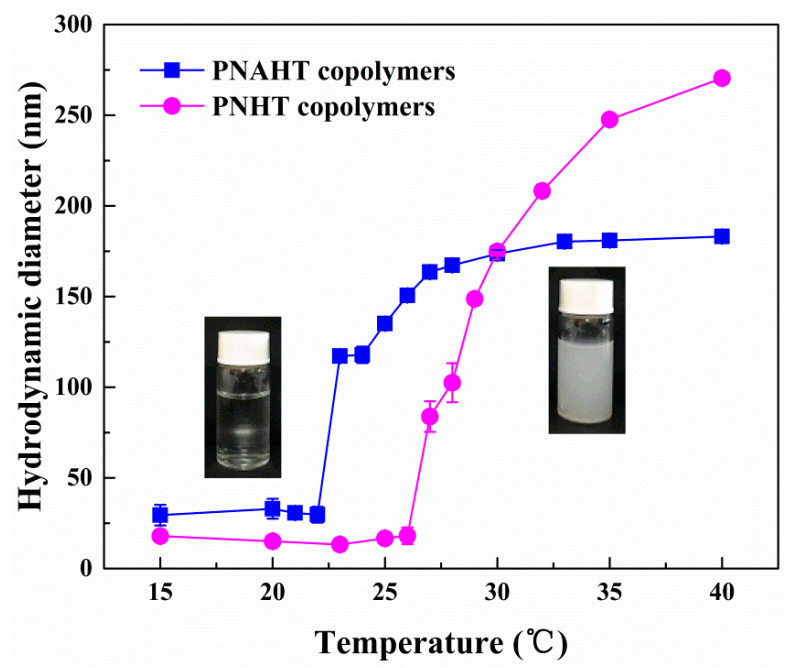

Figure 5. Changes in $\mathrm{D}_{\mathrm{AH}}$ of PNAHT and PNHT in UHQ water as plotted with temperature.

Figure 6 showed that $\mathrm{D}_{\mathrm{AH}}$ of PNAHT copolymers decreased as $\mathrm{pH}$ increased at 20 and $30{ }^{\circ} \mathrm{C}$, and two variation trend curves started to be basically overlapped from $\mathrm{pH}$ of 8.0. When $\mathrm{pH}$ exceeded 9.0, $\mathrm{D}_{\mathrm{AH}}$ of the nanoparticles dropped to around $19 \mathrm{~nm}$, which might be due to the enhanced electrostatic repulsion and increased water solubility, proving that PNAHT copolymers were hydrated with charged single chains at this moment, thus it could be deduced that $\mathrm{p} K_{\mathrm{a}}$ of the resultant copolymers was still within 8.0 9.0. At either 20 or $30^{\circ} \mathrm{C}, \mathrm{D}_{\mathrm{AH}}$ of the agglomerates would be larger in more acidic environment, owing to the fact that copolymer aggregation was heightened by increasing hydrophobic interactions between PBA groups. When the ambient temperature was $30^{\circ} \mathrm{C}$ and $\mathrm{pH}$ was lower than $\mathrm{p} K_{\mathrm{a}}$ of AAPBA, $\mathrm{D}_{\mathrm{AH}}$ of PNAHT copolymers was significantly higher than the results obtained at $20^{\circ} \mathrm{C}$ with the same $\mathrm{pH}$. This was mainly because the molecular chains of PNAHT copolymers were restricted by hydrated hydrogen bonds at $20^{\circ} \mathrm{C}, \mathrm{D}_{\mathrm{AH}}$ of the agglomerates could not be infinitely expanded with the maximum value of $173 \mathrm{~nm}(\mathrm{PDI}=0.107)$. However at $30^{\circ} \mathrm{C}$, the emerging nonhydrated hydrogen bonds and hydrophobic interactions resulted in larger nanoparticles with the maximum of $716 \mathrm{~nm}$ $(\mathrm{PDI}=0.088)$.

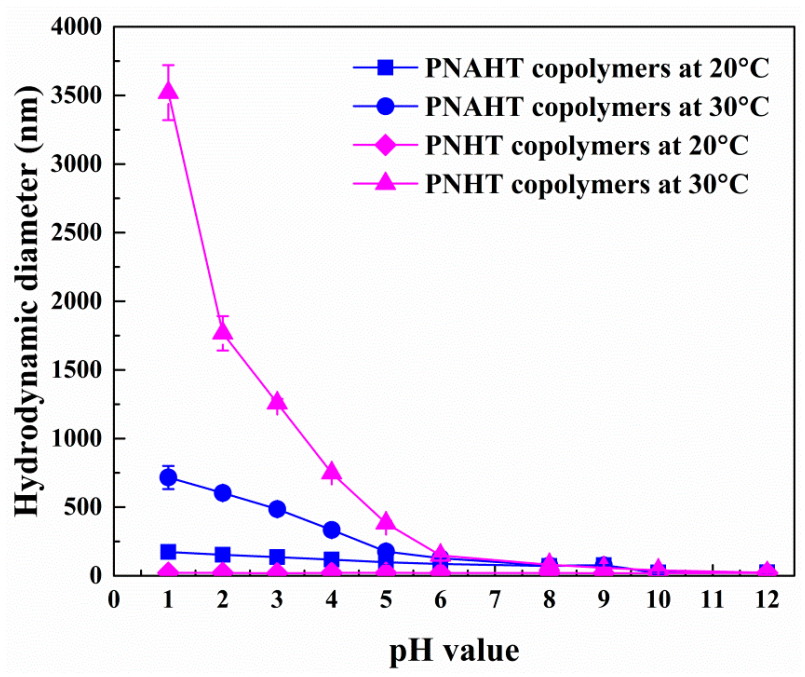

Figure 6. Changes in $\mathrm{D}_{\mathrm{AH}}$ of PNAHT and PNHT copolymers as plotted with $\mathrm{pH}$ value at 20 and $30^{\circ} \mathrm{C}$. 
Figure 6 also indicated no obvious changes in $\mathrm{D}_{\mathrm{AH}}$ of PNHT copolymers along with $\mathrm{pH}$ at $20{ }^{\circ} \mathrm{C}$. No ascertainable aggregation or precipitation was detected throughout the entire $\mathrm{pH}$ range $(1.0 \sim 12.0)$ at lower temperature. The hydrated hydrogen bonds developed by water molecules and hydrophilic groups of PNHT copolymers still played principal roles to effectively keep the dimension and structure of single chains of the copolymers. When the temperature rose to $30^{\circ} \mathrm{C}$ and $\mathrm{pH}$ was less than 6.6, $\mathrm{D}_{\mathrm{AH}}$ of PNHT copolymers would rapidly increase with the declining $\mathrm{pH}$. Similarly to the situations in UHQ water, hydrophobic interactions between isopropyl groups and hydrogen bonds between amide bonds had gradually replaced the hydrated hydrogen bonds. The synergistic effect of inter/intramolecular forces triggered interchain aggregation and intrachain collapse. If in UHQ water, there were still massive hydrated hydrogen bonds, restricting further aggregation of PNHT copolymers, thus the sizes of the agglomerations could be increased only to a certain extent. However, intervention of $\mathrm{HCl}$ changed the action mode of solutions on copolymers [29]. By destroying hydrogen bonds between copolymers and water molecules, $\mathrm{HCl}$ enables hydrophobic interactions and nonhydrated hydrogen bonds to become dominant acting forces, accordingly intensifies copolymer aggregation at elevated temperatures. Higher temperature or more concentration of $\mathrm{HCl}$ (lower $\mathrm{pH}$ ) gives rise to greater damage to hydrated hydrogen bonds, so larger aggregates will be observed. It was reasonably explained that $\mathrm{D}_{\mathrm{AH}}$ of the agglomerations in $\mathrm{UHQ}$ water only reached $270 \mathrm{~nm}(\mathrm{PDI}=0.050)$ whilst $\mathrm{D}_{\mathrm{AH}}$ was up to $3520 \mathrm{~nm}(\mathrm{PDI}=0.062)$ in $\mathrm{HCl}$ solution at higher temperature. Nevertheless, when the temperature was higher than $30^{\circ} \mathrm{C}$ and $\mathrm{pH}$ exceeded 6.6, PNHT copolymers ionized into negative ions via deprotonation. The increasing concentration of hydroxide ions accelerated the ionization of the copolymers, leading to a large number of charged nanoparticles in aqueous solution. The effect of electrostatic repulsion reduced copolymer aggregation, so as to reduce the sizes of particle clusters.

From the above experimental results, it was clear that $\mathrm{D}_{\mathrm{AH}}$ of PNAHT copolymers kept changing over $\mathrm{pH}$ and was independent of temperature, whereas steep declines in $\mathrm{D}_{\mathrm{AH}}$ of PNHT copolymers with the increase of $\mathrm{pH}$ occurred only at the temperature above LCST.

\subsubsection{Copolymers in Glucose Solution}

Considering that LCST for PNAHT and PNHT copolymers in UHQ water were around 23 and $27^{\circ} \mathrm{C}$ while $\mathrm{p} K_{\mathrm{a}}$ were within 8.0 9.0 and 6.0 7.0, the working aqueous solutions with temperatures of 20 and $30^{\circ} \mathrm{C}$, pH of 4.0 and 10.0 and glucose concentration of $0 \sim 6.0 \mathrm{mg} \cdot \mathrm{mL}^{-1}$ were selected to investigate the glucose responsiveness of the copolymers in this study. Figure 7 displayed $\mathrm{D}_{\mathrm{AH}}$ changes of both copolymers under different conditions of temperatures, $\mathrm{pH}$ values and glucose concentrations. It could be observed in Figure 7A, changes in $\mathrm{pH}$ value and glucose concentration had no significant impacts on $\mathrm{D}_{\mathrm{AH}}$ of PNHT copolymers at $20^{\circ} \mathrm{C}$, and the copolymers always exhibited hydrated single chains. At $20^{\circ} \mathrm{C}$ with $\mathrm{pH}$ of 4.0, $\mathrm{D}_{\mathrm{AH}}$ of PNAHT copolymers had very low dependence of glucose concentration. PNAHT copolymers presented in the form of agglomeration at this moment, owing to the reason when $\mathrm{pH}$ was lower than $\mathrm{p} K_{\mathrm{a}}$ of $\mathrm{AAPBA}$, the hydrophobic uncharged PBA groups were difficult to react with cis dihydroxy groups. Therefore, glucose addition would not contribute to the rise of copolymer sizes. However, at $20^{\circ} \mathrm{C}$ with $\mathrm{pH}$ of $10.0, \mathrm{D}_{\mathrm{AH}}$ of PNAHT copolymers increased with the increasing glucose concentration, and the maximum size was twice as much as the initial value of $\mathrm{D}_{\mathrm{AH}}$ around $18 \mathrm{~nm}$. As mentioned above, the combined impact of hydrophobic interactions and hydrogen bonds did not allow PNAHT copolymers to stretch themselves in UHQ water as they did in absolute ethanol, therefore copolymer sizes in UHQ water were lower than that in absolute ethanol. However, PBA groups would be converted into hydrophilic and negatively-charged phenyl borate esters in the presence of glucose. The electrostatic repulsion and hydrated hydrogen bonds enabled PNAHT copolymers with single chains to be more unfolded. Furthermore, higher glucose concentration gave rise to stronger acting forces, accordingly leading to more outstretched molecular chains of the copolymers, hence it was macroscopically reflected in the continuous expanding of copolymer sizes. The results implied that PNAHT copolymers had a glucose-stimulated response. 
As shown in Figure 7B, $\mathrm{D}_{\mathrm{AH}}$ of PNHT copolymers in the aqueous solution with working $\mathrm{pH}$ of 4.0, was significantly larger than that in the solution with $\mathrm{pH}$ of 10.0 at $30^{\circ} \mathrm{C}$, but addition of glucose with the increasing concentration did not cause the copolymers to respond. At $30^{\circ} \mathrm{C}$ with $\mathrm{pH}$ of 4.0 , $\mathrm{D}_{\mathrm{AH}}$ of PNAHT copolymers did not show clear changes with the variation of glucose concentration, but the acidic media with the temperature higher than LCST facilitated the copolymers to gather together. At $30^{\circ} \mathrm{C}$ with $\mathrm{pH}$ of 10.0, the variation trend for $\mathrm{D}_{\mathrm{AH}}$ of PNAHT copolymers plotting with glucose concentration was consistent with the results under the condition of $20^{\circ} \mathrm{C}$ at $\mathrm{pH} 10.0$, which also confirmed that PNAHT copolymers had a response to glucose. For PNAHT copolymers, effective glucose response could only have occurred at the ambient $\mathrm{pH}$ above $\mathrm{p} K_{\mathrm{a}}$ of AAPBA, and the ability to respond increased with the increase of glucose concentration, but it did not associate with temperature changes. The dimension and conformation of PNAHT and PNHT copolymers under different working conditions were summarized in Table 2 .
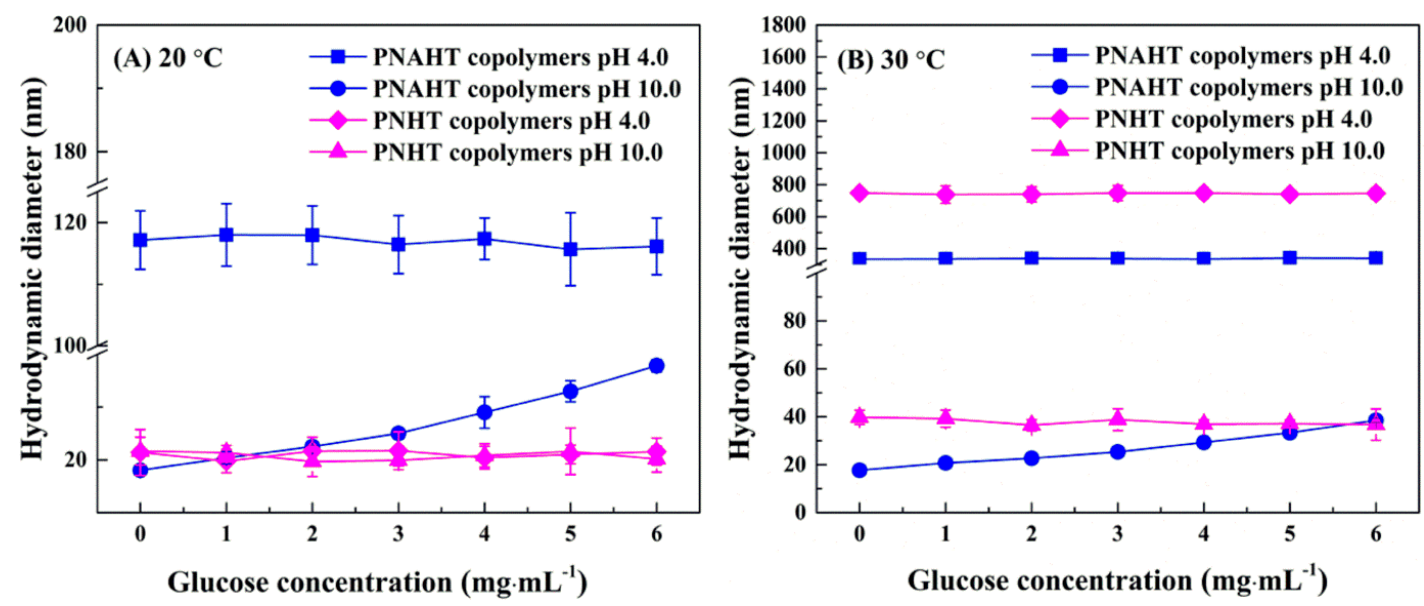

Figure 7. Changes in $\mathrm{D}_{\mathrm{AH}}$ of PNAHT and PNHT copolymers as plotted with glucose concentration at different temperature and $\mathrm{pH}$.

\subsubsection{Smart Responsive Behaviors of Copolymers}

PNAHT copolymers contained temperature-responsive PNIPAAm and glucose-responsive AAPBA, so they independently or simultaneously exhibited multiple responses to temperature, $\mathrm{pH}$ and glucose under suitable conditions. Regardless of whether the ambient temperature exceeded LCST or not in the absence of glucose, copolymer $\mathrm{D}_{\mathrm{AH}}$ could shift with the changes of environmental $\mathrm{pH}$, thus PNAHT copolymers had shown temperature and $\mathrm{pH}$-stimuli responsiveness; only if $\mathrm{pH}$ of working solutions was above $\mathrm{p} K_{\mathrm{a}}$ of AAPBA, the reversible covalent binding between charged copolymers and glucose could be formed, indicating that PNAHT copolymers were temperature-, $\mathrm{pH}-$ and glucose-sensitive, whereas the copolymers were hesitant to bind with glucose at relatively lower $\mathrm{pH}$, which had limited capability to response. $\mathrm{D}_{\mathrm{AH}}$ of PNHT copolymers fell sharply as $\mathrm{pH}$ grew when the temperature was higher than LCST, revealing that the copolymers had high sensitivity to temperature and $\mathrm{pH}$, whereas the copolymers had failed to respond to acidic or alkaline media at lower temperature. Furthermore, thermos-responsive polymers were not dependent on glucose concentration in any case. It can be concluded that the responding of PNIPAAm and PBA to temperature, $\mathrm{pH}$ and glucose can be activated only under special conditions; there is no response if the activation conditions are not satisfied. Therefore, it is necessary to adjust the environmental factors to the optimal conditions to give full play their intelligent responsive performances when applied.

In summary, the major forces affecting temperature and glucose responsive behaviors of PNAHT and PNHT copolymers, include hydrated hydrogen bonds, non-hydrated hydrogen bonds, hydrophobic interactions, electrostatic interactions and so on. When the temperature is lower than LCST of the copolymers, hydrated hydrogen bonds formed by water molecules and hydrophilic groups 
including amide bonds, hydroxyl groups and siloxane groups, maintain the structural organization of PNAHT and PNHT copolymers with single chains or oligomers, while hydrophobic interactions between PBA groups cause the intrachain coiling of copolymer segments to slightly decrease the copolymer sizes. When the temperature is higher than the LCST of the copolymers, nonhydrated hydrogen bonds between amide bonds and hydrophobic interactions between isopropyl groups and PBA groups, trigger intermolecular aggregation and intramolecular collapse of copolymer segments, resulting in the fact that $\mathrm{D}_{\mathrm{AH}}$ of the copolymers will be multiplied several times. When $\mathrm{pH}$ is lower than $\mathrm{pK}$ a of AAPBA, $\mathrm{HCl}$ addition severely destroys hydrated hydrogen bonds, eventually helping non-hydrated hydrogen bonds and hydrophobic interactions become dominant driving forces, even if the temperature is lower than LCST, PNAHT copolymers will gather together to some extent. When $\mathrm{pH}$ is higher than $\mathrm{p} \mathrm{K}_{\mathrm{a}}$ of the resultant copolymers, introduction of $\mathrm{NaOH}$ or glucose changes the ionization equilibrium of the copolymers, correspondingly forming a large amount of charged hydrophilic nanoparticles. The emerging electrostatic repulsions and dramatically increased water solubility inhibit copolymer aggregation, accordingly cause the agglomerates to dissociate into single-stranded or oligomeric forms and make their conformations more stretched. In conclusion, the dimension and configuration of temperature or glucose responsive copolymers are the results of synergistic effects of various inter/intramolecular acting factors.

Table 2. Dimension and conformation of PNAHT and PNHT copolymers under different conditions.

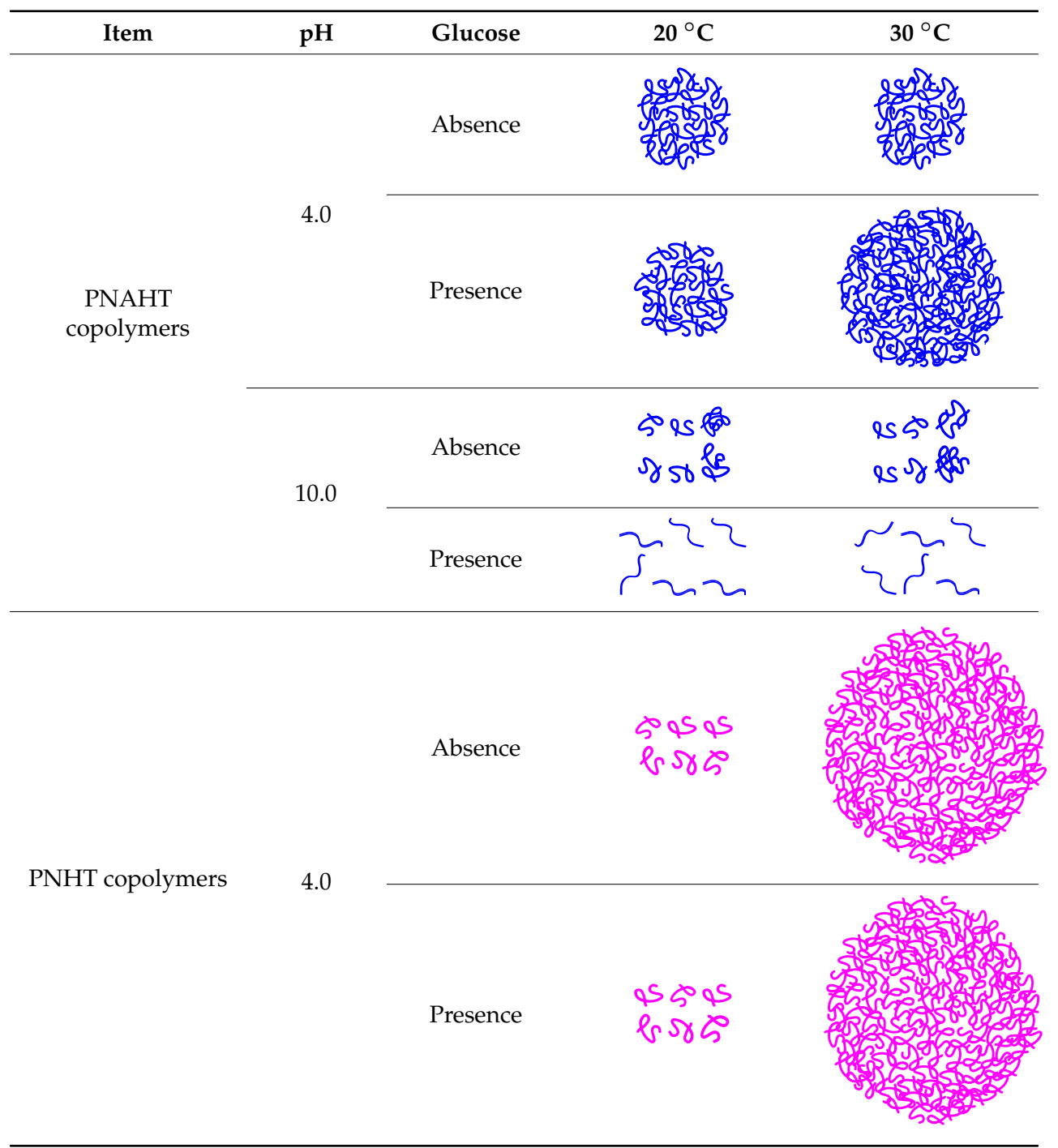


Table 2. Cont.

\begin{tabular}{|c|c|c|c|c|}
\hline Item & $\mathrm{pH}$ & Glucose & $20{ }^{\circ} \mathrm{C}$ & $30{ }^{\circ} \mathrm{C}$ \\
\hline \multirow{2}{*}{ PNHT copolymers } & \multirow{2}{*}{10.0} & Absence & 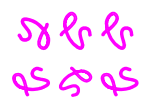 & ind \\
\hline & & Presence & $\begin{array}{l}28 \& \\
f \Omega c\end{array}$ & \\
\hline
\end{tabular}

\subsection{Morphology and Size of Copolymer Particles}

DLS results showed that $\mathrm{D}_{\mathrm{AH}}$ of PNAHT and PNHT copolymers varied significantly in different working solutions. For more clarity, the clean glass coverslips were dipping coated with the copolymer particles in diverse states, and then the coated surfaces were scanned by AFM. In order to eliminate experimental error, the same copolymer concentration and dipping speed were applied in coating processes. Furthermore, all matter became inert and incapable of reaction at the temperature upper limit of $37^{\circ} \mathrm{C}$ in the air. The state of the copolymers deposited on the glass surfaces would be somewhat different from those in aqueous solutions, but fast drying was employed to keep their original shapes as much as possible.

(A)
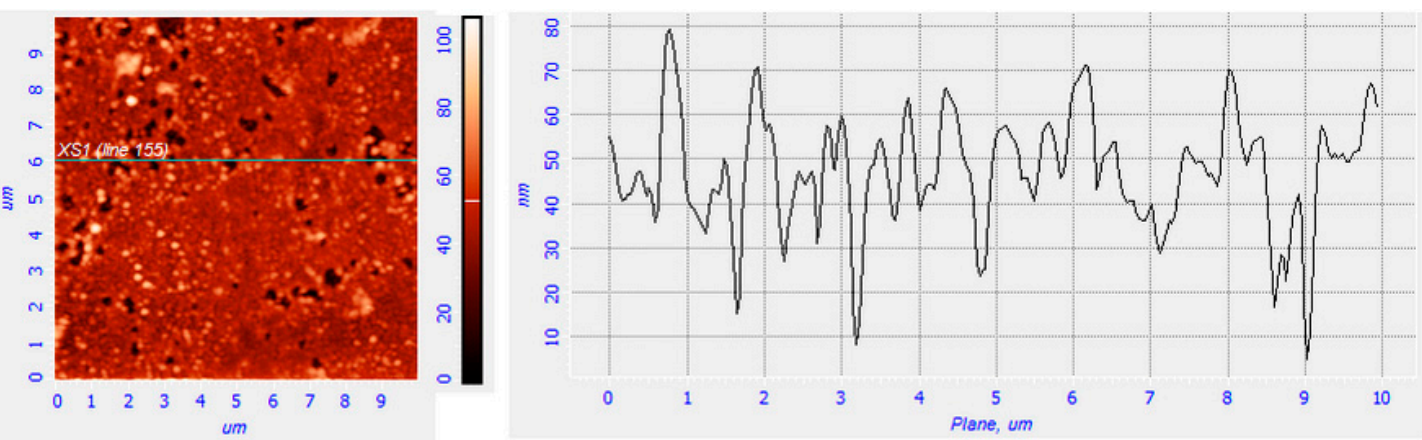

(B)
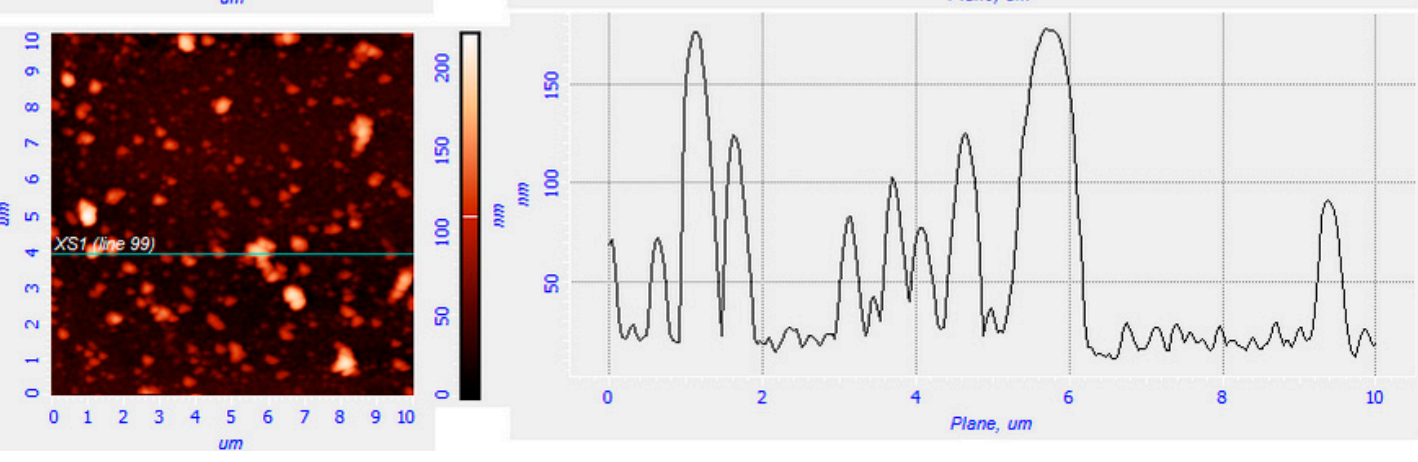

Figure 8. AFM images for glass surfaces with particle deposition of PNHT copolymers in UHQ water at $20^{\circ} \mathrm{C}(\mathbf{A})$ and $37^{\circ} \mathrm{C}(\mathbf{B})$.

Note that this project was not designed to detect the evenness of coating surfaces, so roughness made no sense. It was limited to the discussion of peak heights which reflected the typical particle sizes of the copolymer particles in this study. The height curve of X-cross section was randomly selected in each condition. The AFM images for glass surfaces with particle deposition of PNHT copolymers in UHQ water at $20^{\circ} \mathrm{C}$ (Figure $8 \mathrm{~A}$ ) and $37^{\circ} \mathrm{C}$ (Figure 8B) were taken as examples, as shown in Figure 8 . By comparison, Figure 8A illustrated the peak heights ranging from 0 to $100 \mathrm{~nm}$ with the most peaks appeared at $30 \sim 50 \mathrm{~nm}$, and relatively homogeneous tiny particles basically covered with the glass substrate (dark regions), whereas Figure $8 \mathrm{~B}$ displayed the peak heights distributing from 0 to $200 \mathrm{~nm}$ 
with the peak centered at 140 160 nm, and white or almost white particles were scattered within the dark regions, which left behind greater exposed part of glass surfaces. The AFM results indicated that the particles of PNHT copolymers derived from UHQ water at $20^{\circ} \mathrm{C}$ were more plentiful in number and smaller in size than those at $37^{\circ} \mathrm{C}$. The average particle sizes of PNHT copolymers at $37^{\circ} \mathrm{C}$ were up to several times larger than those at $20^{\circ} \mathrm{C}$, because PNHT copolymers became reunited under the temperature above LCST but hydrated at lower temperature. The phenomenon was in agreement with DLS data. Similar findings were confirmed in other groups of PNAHT and PNHT copolymers.

\section{Conclusions}

The P(NIPAAm-co-AAPBA-co-HPM-co-TMSPM) and P(NIPAAm-co-HPM-co-TMSPM) copolymers were synthesized by free radical polymerization. FTIR spectra showed the characteristic functional groups of the resultant copolymers, such as amide bonds, isopropyl groups, siloxane bonds, hydroxyl groups and ester groups for both copolymers, and phenylboronic acid groups only for PNAHT copolymers. The molar ratios of NIPAAm, AAPBA, HPM and TMSPM in the final products were confirmed by ${ }^{1} \mathrm{H}-\mathrm{NMR}$ spectra to be 20:1:1:1 and 20:0:1:1 for PNAHT and PNHT copolymers. The GPC results indicated that the molecular weight distributions of both copolymers were relatively narrow, however, the molecular weight and polymerization degree of PNAHT copolymers were less than that of PNHT copolymers due to stereo-hindrance effect of AAPBA. The intelligent responsive behaviors of the copolymers in aqueous solutions with different temperature, $\mathrm{pH}$ value and glucose concentration were studied by DLS and AFM. The results demonstrated that PNHT copolymers were thermo- and $\mathrm{pH}$-sensitive, whereas PNAHT copolymers had triple responses to temperature, $\mathrm{pH}$ and glucose under appropriate conditions. Furthermore, the introduction of AAPBA into PNIPAAm segments lowered the molecular weight of the resultant copolymers, intensified the interchain aggregation of the nanoparticles, and reduced the LSCT of the composites. It could be also concluded that the dimension, conformation and further LCST of the copolymers are affected by hydrous hydrogen bonds, nonhydrous hydrogen bonds, hydrophobic interactions and electrostatic interactions. Hydrated hydrogen bonds maintain the size and morphology of the nanoparticles with single chains or oligomers, nonhydrated hydrogen bonds and hydrophobic interactions lead to intermolecular agglomeration and intramolecular crimping, and electrostatic repulsions suppress intermolecular stacking and promote the extension of molecular segments.

Acknowledgments: This work was supported by National Natural Science Foundation of China (21604034) and (31570097), Doctoral Scientific Research Foundation of Liaoning Province of China (20170520391), and General Scientific Research Program of Department of Education of Liaoning Province of China (LSNYB201619).

Author Contributions: Lei Yang and Xiaoguang Fan conceived and designed the experiments; Jiaxing Li and Fei Wang performed the experiments; Jing Zhang analyzed the data; Zhanyong Wang contributed analysis tools; Jiaxing Li and Lei Yang wrote the paper.

Conflicts of Interest: The authors declare no conflicts of interest.

\section{References}

1. Yang, H.W.; Lee, A.W.; Huang, C.H.; Chen, J.K. Characterization of poly(N-isopropylacrylamide)-nucleobase supramolecular complexes featuring bio-multiple hydrogen bonds. Soft Matter 2014, 10, 8330-8340. [CrossRef] [PubMed]

2. Blanco, M.D.; Guerrero, S.; Benito, M.; Fernández, A.; Teijón, C.; Olmo, R.; Katime, I.; Teijón, J.M. In vitro and in vivo evaluation of a folate-targeted copolymeric submicrohydrogel based on $\mathrm{N}$-isopropylacrylamide as 5-Fluorouracil delivery system. Polymers 2011, 3, 1107-1125. [CrossRef]

3. Pandiyarajan, C.K.; Genzer, J. Effect of network density in surface-anchored poly( $N$-isopropylacrylamide) hydrogels on adsorption of fibrinogen. Langmuir 2017, 33, 1974-1983. [CrossRef] [PubMed]

4. Zhang, J.; Peng, C.A. Poly( $N$-isopropylacrylamide) modified polydopamine as a temperature-responsive surface for cultivation and harvest of mesenchymal stem cells. Biomater. Sci. 2017, 5, 2310-2318. [CrossRef] [PubMed] 
5. Barnes, A.L.; Genever, P.G.; Rimmer, S.; Coles, M.C. Collagen-poly(N-isopropylacrylamide) hydrogels with tunable properties. Biomacromolecules 2016, 17, 723-734. [CrossRef] [PubMed]

6. Ma, R.J.; Yang, H.; Li, Z.; Liu, G.; Sun, X.C.; Liu, X.J.; An, Y.L.; Shi, L.Q. Phenylboronic acid-based complex micelles with enhanced glucose-responsiveness at physiological $\mathrm{pH}$ by complexation with glycopolymer. Biomacromolecules 2012, 13, 3409-3417. [CrossRef] [PubMed]

7. Wang, X.; Wei, B.; Cheng, X.; Wang, J.; Tang, R. Phenylboronic acid-decorated gelatin nanoparticles for enhanced tumor targeting and penetration. Nanotechnology 2016, 27, 385101. [CrossRef] [PubMed]

8. Bajgrowicz-Cieslak, M.; Alqurashi, Y.; Elshereif, M.I.; Yetisen, A.K.; Hassan, M.U.; Butt, H. Optical glucose sensors based on hexagonally-packed 2.5-dimensional photonic concavities imprinted in phenylboronic acid functionalized hydrogel films. RSC Adv. 2017, 7, 53916-53924. [CrossRef] [PubMed]

9. Tu, X.Y.; Meng, C.; Liu, Z.; Sun, L.; Zhang, X.S.; Zhang, M.K.; Sun, M.R.; Ma, L.W.; Liu, M.Z.; Wei, H. Synthesis and phase transition of poly( $N$-isopropylacrylamide)-based thermo-sensitive cyclic brush polymer. Polymers 2017, 9, 301. [CrossRef]

10. Berne, B.J.; Pecora, R. Dynamic Light Scattering: With Applications to Chemistry, Biology, and Physics; Courier Dover Publications: New York, NY, USA, 2000; ISBN 0-486-41155-9.

11. Qiu, X.P.; Kwan, C.M.S.; Wu, C. Laser light scattering study of the formation and structure of poly(N-isopropylacrylamide-co-acrylic acid) nanoparticles. Macromolecules 1997, 30, 6090-6094. [CrossRef]

12. Özyürek, Z.; Voit, B.; Krahl, F.; Arndt, K.-F. Thermoresponsive aggregation behavior of NiPAAm/glyco monomer block copolymers studied by dynamic light scattering. e-Polymers 2010, 10, 482-494. [CrossRef]

13. Śliwa, T.; Jarzębski, M. Dynamic light scattering investigation of Pnipam-Co-Maa microgel solution. Curr. Top. Biophys. 2015, 37, 29-33. [CrossRef]

14. Wang, D.; Liu, T.; Yin, J.; Liu, S.Y. Stimuli-responsive fluorescent poly( $N$-isopropylacrylamide) microgels labeled with phenylboronic acid moieties as multifunctional ratiometric probes for glucose and temperatures. Macromolecules 2011, 44, 2282-2290. [CrossRef]

15. Farooqi, Z.H.; Wu, W.T.; Zhou, S.Q.; Siddiq, M. Engineering of phenylboronic acid based glucose-sensitive microgels with 4-Vinylpyridine for working at physiological $\mathrm{pH}$ and temperature. Macromol. Chem. Phys. 2011, 212, 1510-1514. [CrossRef]

16. Farooqi, Z.H.; Khan, A.; Siddiq, M. Temperature-induced volume change and glucose sensitivity of poly[(N-isopropylacry-lamide)-co-acrylamide-co-(phenylboronic acid)] microgels. Polym. Int. 2011, 60, 1481-1486. [CrossRef]

17. Wu, Q.; Wang, L.; Yu, H.J.; Chen, Z.F. The synthesis and responsive properties of novel glucose-responsive microgels. Polym. Sci. Ser. A 2012, 54, 209-213. [CrossRef]

18. Tang, Y.C.; Wu, J.H.; Duan, J.X. The micellization and dissociation transitions of thermo-, pH- and sugar-sensitive block copolymer investigated by laser light scattering. eXPRESS Polym. Lett. 2012, 6, 647-656. [CrossRef]

19. Yang, L.; Liu, T.Q.; Song, K.D.; Wu, S.; Fan, X. Effect of intermolecular and intramolecular forces on hydrodynamic diameters of poly( $N$-isopropylacrylamide) copolymers in aqueous solutions. J. Appl. Polym. Sci. 2013, 127, 4280-4287. [CrossRef]

20. Wedel, B.; Hertle, Y.; Wrede, O.; Bookhold, J.; Hellweg, T. Smart homopolymer microgels: Influence of the monomer structure on the particle properties. Polymers 2016, 8, 162. [CrossRef]

21. Uğuzdoğan, E.; Denkbaş, E.B.; Tuncel, A. RNA-sensitive $N$-isopropylacrylamide/vinylphenylboronic acid random copolymer. Macromol. Biosci. 2002, 2, 214-222. [CrossRef]

22. Dinçer, S.; Köseli, V.; Kesim, H.; Rzaev, Z.M.O.; Pişkin, E. Radical copolymerization of N-isopropylacrylamide with anhydrides of maleic and citraconic acids. Eur. Polym. J. 2002, 38, 2143-2152. [CrossRef]

23. Tang, Y.; Lu, J.R.; Lewis, A.L.; Vick, T.A.; Stratford, P.W. Swelling of zwitterionic polymer films characterized by spectroscopic ellipsometry. Macromolecules 2001, 34, 8768-8776. [CrossRef]

24. Hoare, T.; Pelton, R. Engineering glucose swelling responses in poly( $N$-isopropylacrylamide)-based microgels. Macromolecules 2007, 40, 670-678. [CrossRef]

25. Yang, L.; Pan, F.; Zhao, X.B.; Yaseen, M.; Padia, F.; Coffey, P.; Freund, A.; Yang, L.Y.; Liu, T.Q.; Ma, X.H.; et al. Thermoresponsive copolymer nanofilms for controlling cell adhesion, growth, and detachment. Langmuir 2010, 26, 17304-17314. [CrossRef] [PubMed]

26. Tang, Z.; Guan, Y.; Zhang, Y.J. Contraction-type glucose-sensitive microgel functionalized with a 2-substituted phenylboronic acid ligand. Polym. Chem. 2014, 5, 1782-1790. [CrossRef] 
27. Brewer, S.H.; Allen, A.M.; Lappi, S.E.; Chasse, T.L.; Briggman, K.A.; Gorman, C.B.; Franzen, S. Infrared detection of a phenylboronic acid terminated alkane thiol monolayer on gold surfaces. Langmuir 2004, 20, 5512-5520. [CrossRef] [PubMed]

28. Lai, E.P.; Wang, Y.X.; Wei, Y.; Li, G. Preparation of uniform-sized and dual stimuli-responsive microspheres of poly( $N$-isopropylacrylamide)/poly(acrylic acid) with semi-IPN structure by one-step method. Polymers 2016, 8, 90. [CrossRef]

29. Khan, A.; Alhoshan, M. Preparation and characterization of $\mathrm{pH}$-responsive and thermoresponsive hybrid microgel particles with gold nanorods. J. Polym. Sci. Part A Polym. Chem. 2013, 51, 39-46. [CrossRef]

(C) 2018 by the authors. Licensee MDPI, Basel, Switzerland. This article is an open access article distributed under the terms and conditions of the Creative Commons Attribution (CC BY) license (http:/ / creativecommons.org/licenses/by/4.0/). 